\title{
A STUDY OF REFORESTATION BY SEEDING
}

\author{
By S. R. Schenstrom
}

\section{Cowichan Lake Experiment Station, British Columbia Forest Service}

$\mathrm{T}$

HIS experiment was not undertaken with the primary object of making a careful investigation into different methods of seeding, as a means of establishing forests on logged-off land, but for the purpose of utilizing surplus seed which was on hand at the Forest Service nursery.

This seed was two years old, and apparently of poor quality. However, a sufficient number of seedlings came up to give valuable indications regarding methods of sowing, and the survival of seedlings under different conditions.

The experimental area is situated on the north side of Cowichan Lake, directly opposite the headquarters of the Forest Experiment Station. The site has been burned twice, the second fire, in 1926, destroying a rather good stand of young Douglas Fir, which had become established following an earlier burn. There is no vegetation at present, except an open ground cover of very low Salal and Bracken Fern, and a few other plant species, the ferns seldom being higher than one or two feet. The site is very exposed, both to wind and sun. There are no trees near enough to offer any shelter, and so far as the part subjected to examination is concerned, the ground slopes down about fifteen degrees toward the south-east.

The mineral soil consists of gravel which, due to burn and long exposure, is packed hard. The soil type is a brown soil, which has been fully described in the report* on Experimental Plots 62 to 65, of the Cowichan Lake Station.

SubPlots: Five areas each $0.5 \times 1$ chain were sown in such a way that the seed was broadcasted on four of them-two cedar and two Douglas Fir-and on one subplot the seeding was done in spots.

Only two of these subplots have been re-examined, because the cedar did not show any germination, apparently because of the poor quality of the seed, and only one of the subplots broadcasted with Douglas Fir was chosen as a comparison with the spotted plot.

Time of sowing and weather conditions: The broadcast seeding was done on May 14th, 1929, and the spots were prepared and sown the following day. No seedlings were found the same summer, but in early May, 1930, there were several seedlings in practically every spot. No records were taken at that time or on the occasions when the plot was visited frequently all through the summer, but the mortality is estimated to be in the neighborhood of $50 \%$ up to the time of examination on October 7 and 13, 1930.

The weather during the first season (1929) was characterized by good

*Unpublished MSS., Research Division, B.C. Forest Service. 
precipitation during the period previous to the sowing. June had a rainfall of 3.34 inches which may be considered satisfactory, especially when the daily maximum temperature only occasionally ran up over $80^{\circ}$. The following month, July, was both hotter and drier with a rainfall of only 1.06 inches and fairly high temperatures. This month opened with a period of drought which lasted until the end of September, with very high daily maximum temperatures in August and early September. Rain commenced in October and continued intermittently until the end of the year.

Briefly, the weather during the first summer can be considered favourable for germination till the end of June, but too dry and hot during the rest of the growing season.

It is apparent that the seed used was of such a quality that it was liable to delayed germination. This is the reason why no germination took place the first summer. The seed simply matured during the first half of the season and the last part was too unfavourable for further development. However, everything was in order for an early start in the following spring and at the first examination of 1930, early in May, all spots showed good germina. tion.

Although the second summer was exceptionally unfavourable for the further development of the seedlings, the survival was unexpectedly high. Both the precipitation and maximum temperature were such that very few seedlings were expected to remain alive. The weather conditions during the spring and summer are shown in Table 6.

\section{SOWING IN SQUARE SPOTS.}

Method: The spacing between the spots is 3.7 feet, which gives 154 spots on the area $0.5 \times 1$ chain. This is equivalent to 3,080 spots per acre.

In preparing the spots the ground cover was first removed on an area $1 \mathrm{x}$ $1 \mathrm{ft}$. square and then the mineral soil broken up and mixed to the depth of a grub-hoe blade. On the seedbed thus prepared the sowing was done, the seeds being carefully scattered all over the spot. The seed was mixed in with the soil by scratching the surface with a stick. A slight tramping with the foot then served to establish capillary connection in the soil between the seed and lower layers. To diminish the evaporation from the surface of the spot it was again scratched a little to make the uppermost layer more porous and to keep the air as still as possible.

No records were taken for the number of seeds sown in every spot. How ever, the cutting test of the Fir seed* showed $15 \%$ apparently viable. Supposing the actual germination in the field to be $25 \%$ of this figure, which is rather optimistic in this case with poor seed, the number of seeds required to give five seedlings per spot must have been around 125. This figure is not

*This seed had been collected at Oyster River, B.C., in 1926. 
based upon any records, but is the result of an ocular estimation in the spring. This is of course a very high figure, which is due to the poor quality of the seed. Ten to fifteen seeds should be enough if the germination test gives a value of about 70 or 80 per cent. This last discussion is not based on accurate data, the purpose being only to give a rough idea how many seeds were used in each spot.

When preparing the spots less consideration was paid to a proper spacing than to obtaining the best possible situation from the point of view of protection for the young seedlings. To obtain this, all locations south of logs and other objects reflecting the heat of the sun were avoided. The north-east side of logs, stumps and snags is a good place for spots, giving good protection during the hottest part of the day. If possible no spots were put out in small depressions in order to avoid collection of rain-water in the winter.

Conditions at the end of the first season: As mentioned before, the plots were visited several times during the summer, but no records were taken till the 7th of October, 1930.

The examination that day was carried out in such a way that every spot was given a number which was written on a label beside each spot. Records were taken of the number of seedlings found in every seed-spot, their position and the height of the tallest one. The shade was also studied and three degrees of intensity used. The direction of the shade was observed and recorded as shade from above or from the different main points of the compass. Both the shade on the portion of the spot where the seedings were growing and the shade on the spot as a whole were taken into consideration and kept apart. The species constituting the ground cover were also noted.

At the time of the examination, i.e., when the spots were two summers old, they were comparatively free from invading weeds. No salal or bracken fern were growing on the spots, except in a few cases, but a few other plants giving very little shade, such as Polytrichium, were found rather often. In no case was a spot covered by weeds. Of course this does not mean that roots from surrounding ground cover had not penetrated into the spot, but it is not possible to say to what extent this had happened.

As mentioned before the weather has not been favourable for the survival of the seedlings. The records show that of the total number of spots, 154, as many as 40 have no seedlings at all. This gives a failure of about 26 per cent during the first season because small plants were found in practically every spot when they were visited in the spring.

To find out the probable reason for the mortality the statistics concerning the shade have been worked out, and the sources of shade have been classified as follows: 
Shade from above

\section{(a)}

" " the direction of S.

" " " " " " $"$ S.E. (SE)

" " $"$ "

" " " $"$ "

" " $"$ "

No shade

"N. (N)

(Nil)

Each of these groups is represented by a different number of spots:

\begin{tabular}{|c|c|c|c|c|c|}
\hline a & - & 71 spots & (Including & 9 & O-spots* \\
\hline $\mathrm{S}$ & - & 31 & " & 4 & “" \\
\hline SE & - & 1 spot & " & 0 & “ \\
\hline SW & - & 9 spots & " & 0 & “" \\
\hline E & - & 1 spot & "“ & 0 & “" \\
\hline W & - & $1 "$ & " & 0 & “" \\
\hline $\mathrm{N}$ & - & $1 \quad$ " & “ & 0 & “" \\
\hline \multirow[t]{2}{*}{$\mathrm{Nil}$} & - & $39 \quad "$ & " & 27 & “" \\
\hline & & 154 & & 40 & \\
\hline
\end{tabular}

From this can be seen that only the groups "a," "S" and "Nil" occur to such an extent that mathematically correct conclusions can be drawn.

The average number of seedlings per spot (including also $\mathrm{O}$-spots) was for the different groups:

\begin{tabular}{|c|c|c|c|c|c|}
\hline $\mathrm{a}$ & - & 2.73 & seedlings & per & spot \\
\hline $\mathrm{S}$ & - & 2.26 & " & " & " \\
\hline$(\mathrm{SE}$ & - & 3.) & “ & " & " \\
\hline (SW & - & $3.45)$ & “ & " & " \\
\hline (E & - & 2. ) & “ & “ & “ \\
\hline (W & - & 1. ) & “ & “ & “ \\
\hline$(\mathrm{N}$ & - & 1. ) & “ & “ & “ \\
\hline Nil & - & 0.51 & “ & “ & “ \\
\hline
\end{tabular}

This table gives a very good idea of the importance of shade for the survival of small plants. Spots shaded from above or south have an average number of seedlings per spot of 2.7 and 2.3 respectively, but exposed spots only 0.5 .

The influence of shade-giving agencies can also be traced in the average height of the tallest seedling in each spot:

$\begin{array}{lll}\mathrm{a} & - & 2.0 \text { inches } \\ \mathrm{S} & - & 1.6{ }^{\circ} \\ \mathrm{Nil} & - & 1.4\end{array}$

*O-spots $=$ spots without any seedlings. 
Although the seedlings shaded from south-west are represented by only a small number of spots, i.e., 9, they show an average height which will range between "a" and "S," or 1.9 inches. This is what might be expected, because the hottest time of the day is when the sun is in the S.W. and the shadow from this direction should be more effective than that from the $S$. and about equal to protection from above, provided the shade intensity is the same.

The influence of protection from the S.W. can also be read in the number of seedlings per spot as shown above. Group "S.W." has an average 3.45 plants in each square which is the highest figure shown by any group. It should be noticed that the number of seedlings per spot for group "S.W." does not range between " $a$ " and " $S$ " as does the figure for the height. However, there are more factors determining germination and survival, than those which affect the height growth, on account of which the heights of the seedlings ought to arrange the groups in a better order than does the survival.

To be able to study the influence of shade intensity three degrees were used:

1. Light shade

2. Intermediate

3. Full shade

The various statistics which have been worked up show that both the number of seedlings per spot and the average height of the tallest one in each spot is proportional with the shade intensities as shown in Tables 1 . and 2.

TABLE 1.

NUMBER OF SEEDLINGS PER SPOT DISTRIBUTED BY INTENSITY AND DIRECTION OF SHADE

Direction of Shade Intensity of Shade

$\begin{array}{lccc} & 1 & 2 & 3 \\ \text { a } & 2.4 & 3.4 & (15.0)^{*} \\ \text { S } & 2.2 & 2.6 & (2.0)^{*} \\ \text { SW } & 2.2 & 4.3 & 4.0 \\ \text { Average } & 2.5 & 3.4 & (7.0)\end{array}$

The average for unshaded spots was 0.5

TABLE 2.

AVERAGE HEIGHT OF TALLEST SEEDLING IN EACH SPOT DISTRIBUTED BY INTENSITY AND DIRECTION OF SHADE

Direction of Shade

Intensity of Shade

a

$\begin{array}{lll}1 & 2 & 3\end{array}$

S

$\begin{array}{lll}1.7 & 1.9 & 2.3\end{array}$

$\begin{array}{lll}1.6 & 1.6 \quad 1.9\end{array}$




$\begin{array}{cccc}\mathrm{SW} & (2.7)^{*} & 1.9 & 1.8 \\ \text { Average } & 1.6 & 1.8 & 2.0\end{array}$

The average for the unshaded spots was 1.4

When examining the plots the situations of the seedlings in the spots were recorded and put down in one of the following groups: Scattered, north side, east side, south side, west side and middle of spot.

The number of seedlings and their average height, for these groups, calculated as before, are shown in Table 3.

TABLE 3.

NUMBER OF SEEDLINGS PER SPOT AND THEIR AVERAGE MAXIMUM HEIGHT IN REGARD TO THE PLACE THEY OCCUPY IN THE SPOT.

Place of seedlings in spot

Scattered

N. side of spot

E. " " "

S. " " " "

W. " " "

Middle of spot Spot on N. side of log

Spot on E. side of $\log$ Spot on S. side of $\log$ Spot on W. side of log

It is apparent that in this case also the influence of the shade can be seen. The south side of the spots show the highest number of seedlings and amounts to an average of 3.5 per spot, followed by the "scattered" group with 2.9 . Where the seedlings are grouped in the middle of the spots the mortality seems to be higher; only 1.3 per spot are found. As could be expected, the "north side" group shows the lowest figure, only 1.0 seedlings. However, this group is represented by only two spots and, although the tendency is right, there is no evidence that the figure is correct. The low number of spots depends very likely on poor conditions for both germination and survival along the north side of the spots.

As far as the height growth of the different groups just dealt with is concerned, it can be seen from the above table that "scattered" and "S side" show the same figures of 1.7 inches as an average for the tallest seedling in each spot. This coincidence can be explained by the fact that the tallest *Only one spot. 
seedlings in the group first mentioned are found along the south sides of the spots and thus should show the same ratio of development as the other group. Seedlings growing in the middle are smaller than those just mentioned, showing an average maximum height of 1.3 inches, followed by plants along the north side, with only 1.0 inches. The last figure is, as in the case of the number of seedlings, based only upon two spots, and is not reliable, although the tendency is right.

There are a number of spots which are situated in the shelter of logs lying on the ground. These are not included in the last table, but compiled separately and distributed in the same way. Only the spots on the north side of logs are represented by a number sufficient to make conclusions. This is quite natural, because in carrying out the work the south side was avoided as being more exposed. When comparing these figures with those already derived for other groups, it is apparent that they coincide very well with those from spots shaded from above and spots where the seedlings are scattered, as regards both the number of seedlings and their average maximum heights.

A very interesting point is the influence of lupines upon the development of the seedlings. This genus was growing in the neighborhood of nine spots, three of which were $\mathrm{O}$-spots. The average number of seedlings per spot (figured on all nine) is 2.6, which is close to the average for the whole subplot. But the average height of the tallest seedlings shows a remarkably high figure, 2.9 inches. This is nearly one inch more than for the best shade group. It is probable that the good development of these seedlings is due to the nitrogen available through the legumes. This brings us to the problem of destruction by fire of the humus, which is the main source of the nitrogen which is especially needed by the small plants. There is no doubt that in cases like this where all humus has been destroyed by two fires, the seedlings may starve from lack of nitrogen, unless the presence of special factors, as for instance in this case legumes, will help them.

\section{BROADCAST SOWING.}

The examination of this subplot was carried out by help of a strip run diagonally from the N.W. cornerpost to the S.E. The length of this strip was 73.5 feet and the width 2 feet, which covers an area of 147 square feet. This is only $6.8 \%$ of the area of the whole subplot, which is a rather low figure.

All seedlings were tallied and described in a similar way as was done on the spotted area. 50 seedlings were found on the strip, equivalent to about 15,000 per acre, and their distribution into "shade groups" is very remarkable. Only one of them was found in places without ground cover, all the rest growing among salal and bracken fern. In other words, the influence 
of shade is evident also on this plot. 38 seedlings were shaded from above, only 8 from the direction of south and 3 growing among litter. It is quite logical to find so many seedlings in the group "a" because there are more such locations available.

Seedlings shaded from above are the only ones represented by a suf. ficient number. Still, the average heights of the seedlings for the different groups correspond very well with those from the other subplot where the sowing was done in spots (Table 4.)

TABLE 4.

\section{HEIGHT OF SEEDLINGS IN REGARD TO SHADE} Shade from Avg.

Height,

$\begin{array}{lllll}\text { Broadcast } & 1.9 \text { ins. }(38)^{*} & 1.7 \text { ins. (8) } & 1.3 \text { ins. (1) } & 1.85 \\ \text { Seeding in spots } & 2.0 \text { ins. (62) } & 1.6 \text { ins. (27) } & 1.4 \text { ins. (12) } & 1.82\end{array}$

It should be kept in mind that the heights from the broadcasted plot are based upon all seedlings but the height for the other subplot only upon the tallest seedling in every spot. In other words, the values are not directly comparable, but the tendencies are evident in both cases and assist in under. standing the influence of shade.

The statistics for the three degrees of shade intensity is worked out in Table 5 .

TABLE 5.

AVERAGE HEIGHT OF SEEDLINGS DISTRIBUTED BY DIRECTION AND INTENSITY OF SHADE

Direction of shade

Intensity of shade

$\begin{array}{cllll}\mathrm{a} & 1.8 \text { ins. (17)* } & 2.0 \text { ins. (15) } & 2.1 \text { ins. (6) } \\ \mathrm{S} & 1.5 \text { ins. (5) } & 1.9 \text { ins. (3) } & - & (0) \\ \text { Average } & 1.7 \text { ins. } & 2.0 \text { ins. } & 2.1 \text { ins. }\end{array}$

Table 5 shows the same tendency as the corresponding figures for the other plot, i.e., increase in height with increase in shade.

It has already been mentioned that the average heights are figured somewhat differently for the two subplots. According to this one could expect that the average height for the last plot was higher than the other, especially if the root competition also is considered. However, this is not the case. The broadcasted plot has an average height of 1.85 inches and the seedlings in spots show an average of 1.82 . The difference is not great, but it might be

*Figures in brackets are number of samples. 
expected to have been the other way, and more pronounced. Why this is not the case can be explained by the fact that $83 \%$ of the height samples from the broadcasted plots are in the best shade group, " $\mathrm{a}$," the corresponding figure for the other plot being only $63 \%$. Also, the intensity of the shade is in favour of the first plot. The lowest class, (1), has been the same percentage of samples on both plots, but the highest class, (3), is much more strongly represented on the broadcasted with $17 \%$ as compared with only $3 \%$ on the spotted plat.

\section{CONCLUSIONS.}

There is no doubt that some valuable conclusions can be drawn from the above in spite of the rather unsatisfactory material they have to be based upon, such as very poor seed, few examinations, and other points.

The first and most important factor controlling the survival seems to be the shade. The mortality has been very high wherever the seedlings have been exposed to the sun. Practically no seedlings can be found in such places at the end of the first growing season.

The situation of the seedlings in the spots seems to indicate that root competition is a factor of minor importance. Most roots from surrounding ground cover were cut off when the spots were prepared, but during the two summers past since the establishment of the plot new roots can be expected to have penetrated into the spot at least some distance from the side. At all events, the middle of the spot must be the part best protected from root competition, but this does not seem to favour the survival. As a matter of fact, the central portions of the spots show a much higher mortality than the south and adjoining sides. When drawing the conclusions that root competition is not a factor of importance it must be kept in mind what type of ground cover this refers to, i.e., a rather open vegetation of mainly bracken fern and salal which seldom reaches higher than 2 feet.

The square spot system apparently is not the best one for the conditions under study. Sowing in strips, a foot in length, and having the same width as the grub hoe, would seem to be the most logical method. 26 per cent of $\mathrm{O}$-spots is a very high failure under normal conditions, but the weather conditions during the summer 1930 could hardly have been worse. It is rather astonishing that the mortality was not higher, especially if the poor quality of the seed is taken into consideration. With good seed and the change in method which has been suggested, good results can be expected. Still, the square spot system could be a very good one if the spots after seeding were covered with, for instance, a few branches of wilting bracken fern which will give a good shelter and not pack too dense, and prevent the seedlings from growing up. But considering the minor importance of root competition there is really no reason to retain this more expensive method. 
One factor which has contributed to the comparatively good results is the time of germination. No germination took place in the first summer, following the very late sowing (May 14, 1929.) Apparently the weather did not allow the poor seed to develop enough to start germination, but this took place very early in the spring the following year. This early start, simultaneous with that of most other vegetation, protects the seedlings more from being eaten because more food is available. If the germination takes place in late June, for instance, the seedlings are still very tender while the rest of the vegetation has its tissues more hardened and more protected against sap. sucking insects and other noxious animals. When visiting the plot during the summer no seedlings were found eaten off or seemingly suffering from attacks by animals. An early germination will also enable the seedlings to develop more and to better withstand the drought.

It is obvious that the seedlings on an area burned so severely several times that no humus is left will suffer from lack of nitrogen. The preparing of spots or strips should as a consequence of this be carried out in such a way that the ground cover is removed but not the thin humus which is present. Instead it should be carefully mixed with the mineral soil.

The broadcasted plot has mainly served as a check of the results obtained from the other plot, especially those regarding the influence of shade and root competition. The broadcast sowing is a very wasteful system at present when tree seed is so expensive.

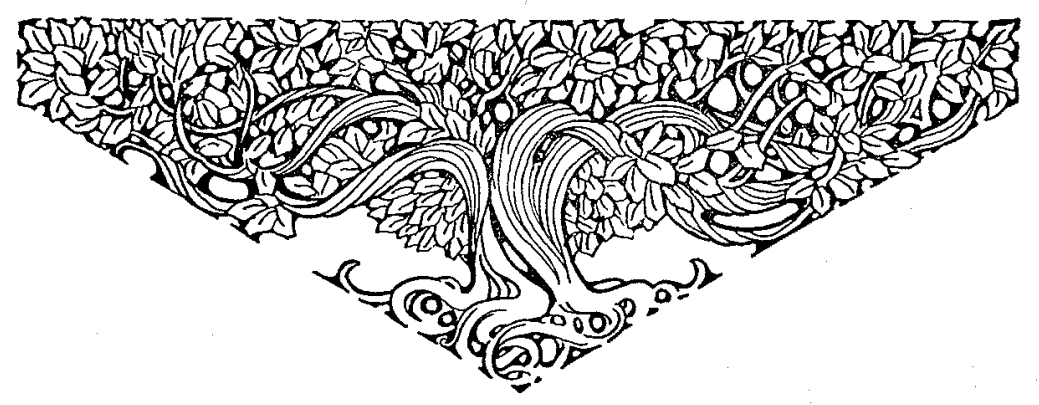

